\title{
latrogenic Fracture of the Lower Jaw: A Rare Complication of Lower Molar Extraction
}

\author{
Radovan Mottl ${ }^{1, *}$, Martina Kunderová ${ }^{1}$, Radovan Slezák ${ }^{1}$, Jan Schmidt ${ }^{1}$
}

\begin{abstract}
latrogenic mandible fracture is a rare complication of a tooth extraction with an incidence between $0.0033-0.0034 \%$. This study retrospectively analyzes a total of 8 patients who underwent lower molar extraction associated with mandible fracture during tooth removal in the period from April 2006 to March 2019. The assessed parameters were age and sex of patients, method of tooth extraction, side distribution of fracture, type of extracted tooth, the position of a lower third molar, presence of bone pathological lesion formed in connection with a tooth, displacement of bone fragments, and sensory impairment in the innervation area of the mental nerve. The position and impaction of the lower third molars were evaluated according to Pell and Gregory's classification and Winter's classification. One fracture was left-sided, and 7 fractures were right-sided. In 6 cases, Winter's extraction elevator was used. In 7 patients, the mandible fracture was treated surgically by performing stable osteosynthesis with the plates and screws. One patient was treated conservatively. This work analyzes the causes of iatrogenic mandible fractures and provides recommendations to reduce the risk of their occurrence.
\end{abstract}

\section{KEYWORDS}

latrogenic fracture; lower jaw; tooth extraction; dental elevator; complications

\section{AUTHOR AFFILIATIONS}

${ }^{1}$ Department of Dentistry, Charles University, Faculty of Medicine in Hradec Králové and University Hospital Hradec Králové, Czech Republic

* Corresponding author: Department of Dentistry, Charles University, Faculty of Medicine in Hradec Králové and University Hospital Hradec Králové, Sokolská 581, 50005 Hradec Králové, Czech Republic; e-mail: radovan.mottl@fnhk.cz

Received: 6 March 2021

Accepted: 18 April 2021

Published online: 30 July 2021

Acta Medica (Hradec Králové) 2021; 64(2): 101-107

https://doi.org/10.14712/18059694.2021.18

(c) 2021 The Authors. This is an open-access article distributed under the terms of the Creative Commons Attribution License (http://creativecommons.org/licenses/by/4.0), which permits unrestricted use, distribution, and reproduction in any medium, provided the original author and source are credited. 


\section{INTRODUCTION}

Extraction of lower permanent molars is a routine surgical procedure. In most cases, the reason for the tooth removal is tooth decay and its complications (pulpitis, apical periodontitis), acute or chronic pericoronitis, less often periodontal disease, and orthodontic treatment (1). However, complications can occur during or after the procedure. The most common non-specific complications of lower molar extractions include alveolar osteitis (alveolitis sicca dolorosa), early or late bleeding after extraction, hematoma, soft tissue contusion, collateral edema, or prolonged healing of the extraction wound. Some complications are rather specific, occurring mainly in association with the extraction of lower third molars that are also called wisdom teeth. Due to the localization of lower third molars, the surgical procedure may lead to an injury of the neurovascular bundle in the canalis mandibulae manifested by bleeding from the mandibular canal or inferior alveolar nerve damage.

A rare and specific complication is also an iatrogenic fracture of the lower jaw, which can occur not only during the operation itself but in the period after the operation as well $(2,3)$. The aim of this work is a retrospective evaluation of the frequency and circumstances of this surgical complication in individuals registered at the Dental Clinic, Charles University, Faculty of Medicine in Hradec Králové and University Hospital Hradec Králové in the years 2006-2019.

\section{MATERIAL AND METHODS}

The retrospectively evaluated group consisted of a total of 8 patients who underwent lower molar extraction associated

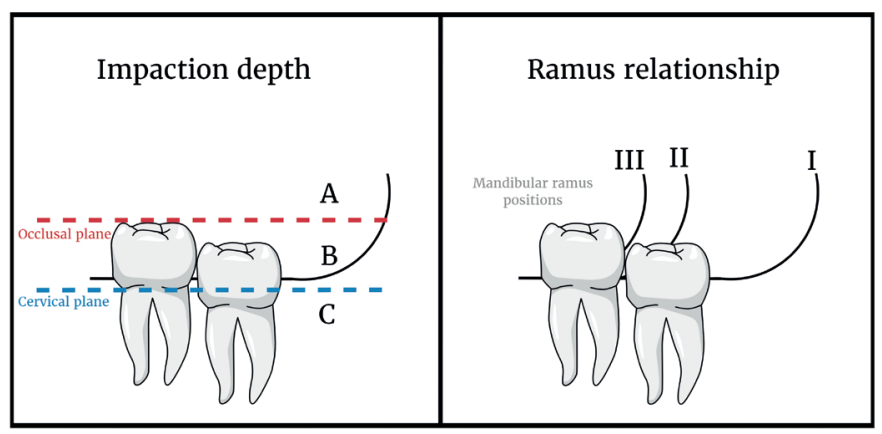

Fig. 1 Pell and Gregory's classification of lower third molars position. with mandibular fracture during the surgery in the period from April 2006 to March 2019. The assessed parameters were age and sex of patients, method of tooth extraction, side distribution of fracture, type of extracted tooth, the position of a lower third molar on the extraoral panoramic radiograph (orthopantomogram), presence of tooth related bone pathological lesion formed (intraosseous odontogenic cyst, chronic periodontitis), displacement of bone fragments, and sensory impairment in the innervation area of the mental nerve. The position and impaction of the lower third molars were evaluated according to the Pell and Gregory's classification (Fig. 1) and Winter's classification (Fig. 2) $(4,5)$. Preoperative radiographs were available in 6 patients.

\section{RESULTS}

In 6 patients, the extraction was performed under local anesthesia -3 of them underwent the extraction in private practices of general dentists, and 3 individuals in the Dental Clinic, University Hospital Hradec Králové. In 2 patients, the extraction was performed under general anesthesia in the Dental Clinic, University Hospital Hradec Králové. In 7 cases, the lower third molar was extracted, and in one case, the lower ankylotic partially erupted second molar was extracted (Fig. 3). The mean age of the patients was 53.2 years and the median age was 54.5 years (range $36-77$ years). The sex distribution of the study sample was 2 males and 6 females. 7 fractures were right-sided, and one fracture was left-sided. 4 fractures were associated with recurrent inflammatory conditions, i.e., pericoronitis, in the anamnesis, and in 3 cases, the presence of a tooth related bone pathological lesion (one odontoma and two dentigerous cysts) was detected in the period before the surgery. In 3 patients, the distoangular position of the lower third molar was determined according to Winter's classification. In 6 cases, Winter's extraction elevator was used to remove the tooth, among other instruments. In 6 patients, jaw fragments were displaced, followed by a unilateral sensory impairment, i.e., paresthesia, located in the innervation area of the mental nerve. In 7 patients, the mandible fracture was treated surgically by performing stable osteosynthesis with the plates and screws. In one patient, it was treated conservatively with intermaxillary fixation. Fractures were healed without complications in all patients, and the patients were followed for two years. The sensitive innervation was fully recovered only in two patients within two years after the procedure.

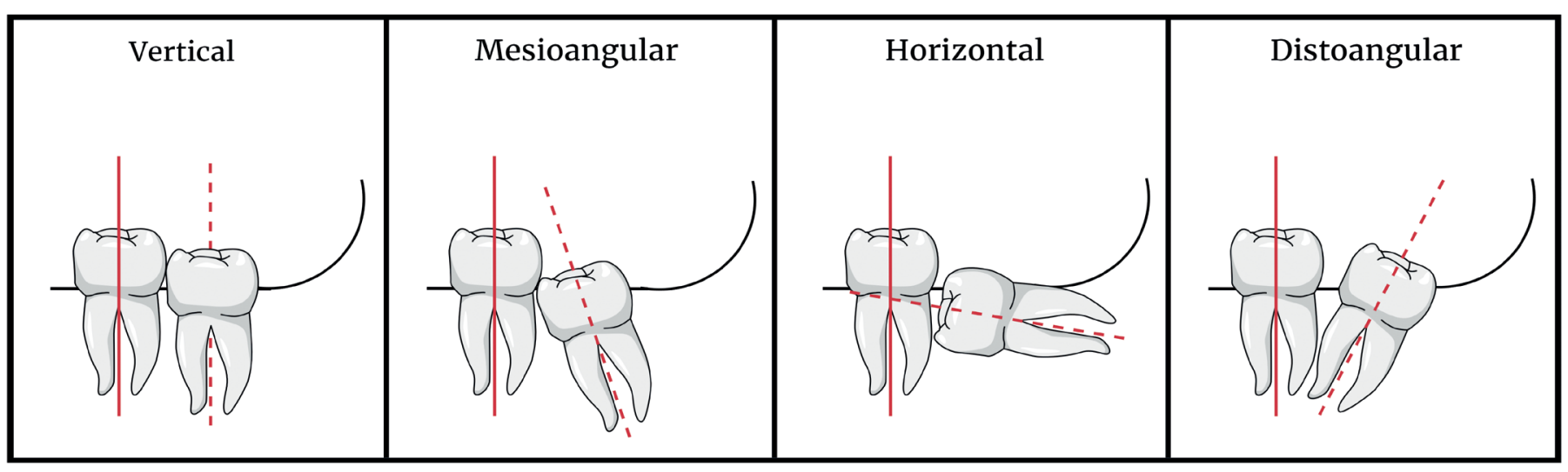

Fig. 2 Winter's classification of lower third molars position. 
Figures 4-6 demonstrate the situation before and after the tooth extraction, and after the treatment in three patients. For this illustration, the most common panoramic radiographs, i.e., orthopantomograms, were used (Fig. 4a-c, $5 a-c, 6 a-b)$.

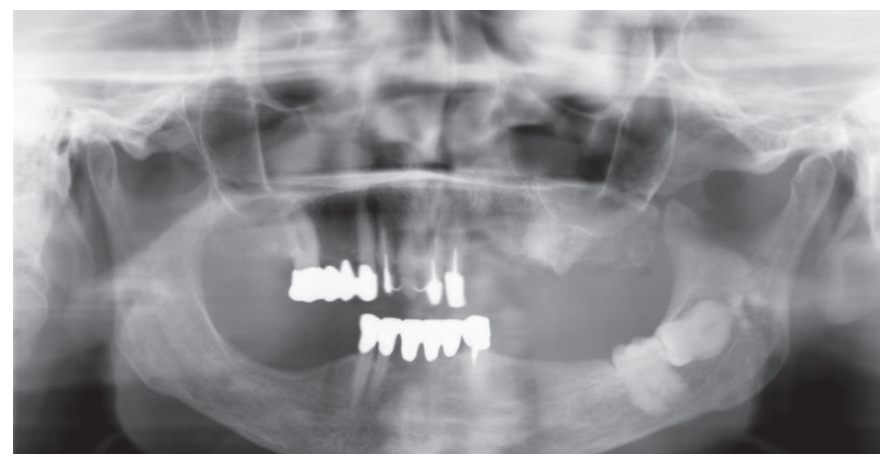

Fig. 3 Panoramic radiograph before the extraction of the tooth 37.

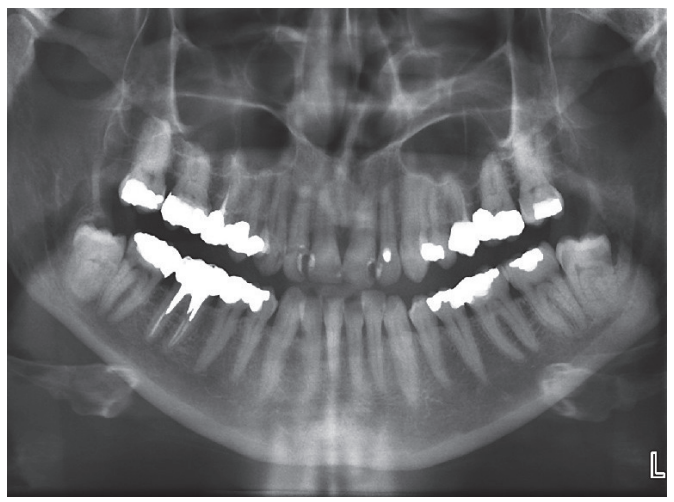

Fig. 4a Panoramic radiograph before the extraction of the tooth 48 in patient No. 3 .

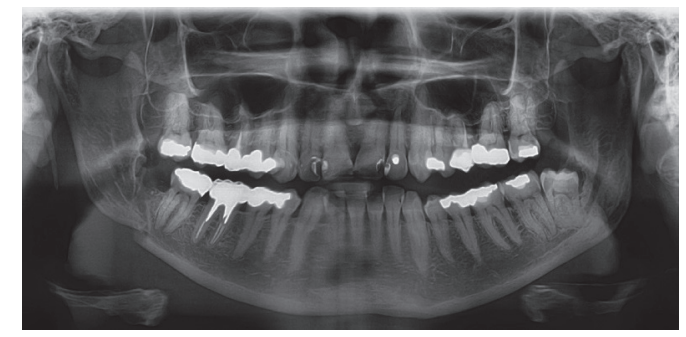

Fig. 4b Panoramic radiograph demonstrating the mandibular fracture after the right-sided lower third molar extraction in patient No. 3.

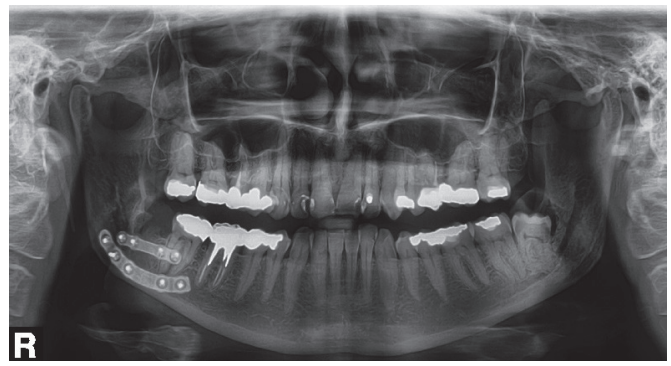

Fig. 4c Panoramic radiograph demonstrating the osteosynthesis of the mandibular fracture after the right-sided lower third molar extraction in patient No. 3 .

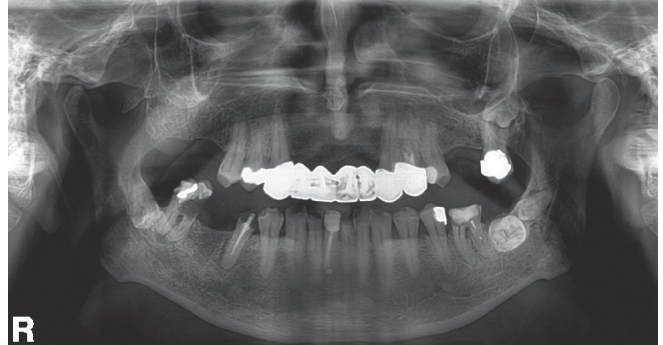

Fig. 5a Panoramic radiograph before the extraction of the teeth 48 and 47 in patient No. 5 .

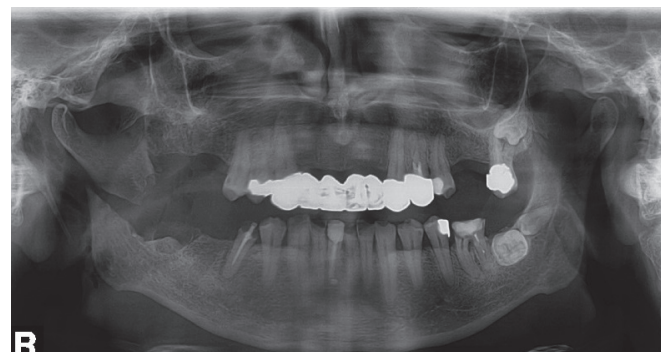

Fig. 5b Panoramic radiograph demonstrating the mandibular fracture after the right-sided lower molars extractions in patient No. 5.

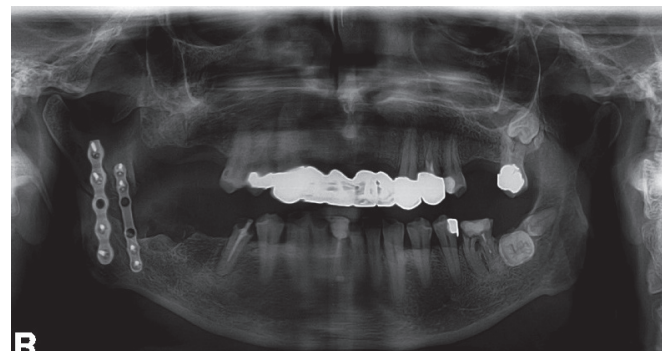

Fig. 5c Panoramic radiograph demonstrating the osteosynthesis of the mandibular fracture after the right-sided lower third molars extractions in patient No. 5 .

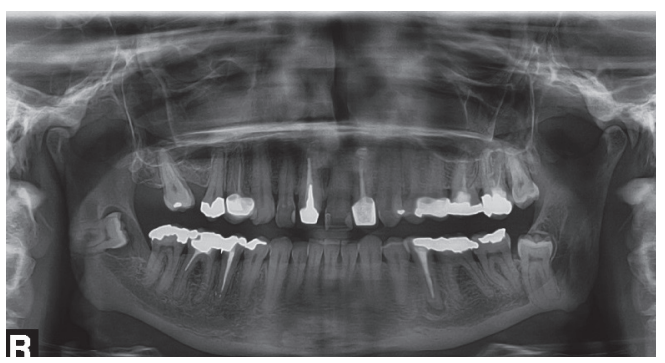

Fig. 6 a Panoramic radiograph before the extraction of the tooth 48 in patient No. 7 .

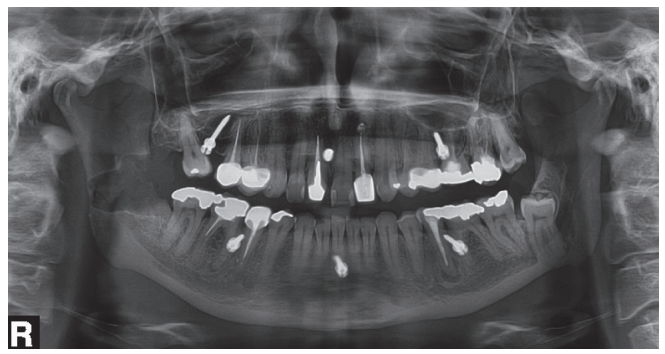

Fig. 6b Panoramic radiograph demonstrating the mandibular fracture after the right-sided lower third molar extraction in patient No. 7. after insertion of IMF screws and intermaxillary fixation with rubber rings. 
The results are summarized in Table 1.

Tab. 1

\begin{tabular}{|c|c|c|c|c|c|c|c|c|c|}
\hline $\begin{array}{c}\text { Patient } \\
\text { Nr. }\end{array}$ & Age & Gender & Side & Tooth & $\begin{array}{r}\text { Presence } \\
\text { of the pathological lesion }\end{array}$ & Localization & Dislocation & $\begin{array}{c}\text { Sensory } \\
\text { impairment }\end{array}$ & $\begin{array}{c}\text { Tooth position according to Pell } \\
\text { and Gregory's classification }\end{array}$ \\
\hline 1 & 38 & W & R & 48 & Yes & Angle & Yes & Yes & not classified \\
\hline 2 & 38 & M & R & 48 & No & Angle & Yes & Yes & C II. \\
\hline 3 & 53 & W & R & 48 & No & Angle & Yes & Yes & B II. \\
\hline 4 & 77 & W & L & 37 & No & Body & Yes & Yes & not classified \\
\hline 5 & 66 & M & R & 48 & No & Ramus & Yes & No & CI. \\
\hline 6 & 62 & W & R & 48 & No & Angle & Yes & Yes & B I. \\
\hline 7 & 36 & W & R & 48 & Yes & Ramus & No & No & C III. \\
\hline 8 & 55 & W & R & 48 & Yes & Angle & Yes & Yes & $\mathrm{CI.}$ \\
\hline
\end{tabular}

\section{DISCUSSION}

The area of the mandibular angle (angulus mandibulae) is an area with lower resistance to fractures. It is due to the fact a transition zone between the toothed and nontoothed part of the mandible is formed here. Additionally, the presence of the third lower molar, which is often incompletely erupted and impacted in the bone, further contributes to bone weakening. By cause of these conditions, approximately $75 \%$ of the iatrogenic mandibular fractures are associated with the lower third molar removal (6). In other parts of the mandible, iatrogenic fractures are also possible. However, in these localisations, iatrogenic fractures are disproportionately rare and associated with other significant bone weaknesses (retained canines and premolars, large bone cysts, benign and malignant tumors, conditions after marginal resection of the mandible, or some bone diseases).

Fracture of the mandible occurring during or after the lower molar extraction is a rare complication of this surgi$\mathrm{cal}$ procedure. According to literature data, the incidence of mandible fractures during tooth extractions ranges from 0.0033 to $0.0034 \%$, while the incidence of fractures occurring after tooth extractions is $0.0042-0.0049 \%$ (7-10). According to Ethunandan et al. is the ratio $1: 2.7$ (11).

Extractions of the lower wisdom teeth are most often performed on patients under 25 years of age. However, in this age group, iatrogenic mandible fractures occur very rarely (11). The findings of our study, in conclusion with the findings of other authors, confirm that a significant risk factor for the occurrence of this complication is older age, with the risk increasing from approximately the age of $36(12-14)$. This fact is explained by an age-related decrease in bone elasticity, narrowing of the periodontal space leading to tooth ankylosis, and also by a more frequent occurrence of pathological lesions in the jawbones, especially odontogenic cysts $(15,16)$. In the group of our study, the mean age of patients with iatrogenic mandible fracture was 53.2 years, and the median was 54.5 years. Such age distribution is only slightly higher than in other studies $(9,12)$.
Regarding sex distribution, perioperative iatrogenic mandibular fractures are more frequently reported in women, with a ratio of $1.3: 1$. In contrast, postoperative iatrogenic mandibular fractures are reported to be more frequent in men, with a ratio of $3.9: 1(11,13,17,18)$. In our study, $75 \%$ of the perioperative iatrogenic mandibular fractures were observed in female subjects. Although our results indicating higher frequency in females correspond with the findings of other authors, the quantitative outcome differs. Such a disparity may be attributed to the limited number of subjects involved in our study.

The presence of an intraosseous pathological lesion was observed in three cases - one benign odontogenic tumor, i.e., odontoma, and two odontogenic dentigerous cysts. In 4 cases, the pericoronary sac enlarged by more than $2 \mathrm{~mm}$ was visible on the radiograph.

Some authors reported an unequal side distribution of iatrogenic mandibular fractures with a higher incidence on the left side $(6,17,19,20)$. This phenomenon may be explained due to more difficult access to the operating field for surgeons with right-hand dominance, which is more frequent in the population. However, the data of our study do not match with their findings as 7 of the fractures were localized on the right side.

Another risk factor for the development of an iatrogenic fracture of the mandible is the impaction level of the extracted tooth. This risk factor is associated not only with lower third molars, but generally with any tooth. According to Izuka et al., the percentage ratio comparing the height of the lower third molar to the remaining height of the mandibular bone measured on the orthopantomogram ranges between $44-84 \%$ (12). Some authors reported on this ratio exceeding $50 \%$ to be associated with a higher risk of mandible fracture $(6,21,22)$. The work of Joshi et al. relates $54 \%$ of iatrogenic mandibular fractures to the removal of lower third molars fully impacted in bone (6). In our study, the ratio of tooth height to the ratio of remaining bone height was more than $50 \%$ in 5 patients, i.e., $62.5 \%$ of the study subjects. Interestingly, the study of Reitzik et al. demonstrates the differences in force leading to the mandible fracture in primate 
(Cercopithecus aethiops) jaws with various levels of third molar eruption. Mandibles with unerupted third molars were found to be significantly weaker compared to the mandibles with erupted third molars. The force required to break the jaw with the impacted third molar was at the level of $60 \%$ of the force required to break the jaw with erupted third molars (23).

The position of lower third molars is also a factor that affects the risk of complications development. According to Winter's classification, the most common position is mesioangular, which is approximately $45 \%$ of all cases, and the least common is the distoangular position, which occurs in the range of $5-12.8 \%(11,24)$. The latter is considered to be the most difficult position for tooth removal and it is also associated with the highest risk of fracture (25). According to Pell and Gregory's classification, the highest risk of jaw fracture is related to the tooth position class B or C and type II or III $(12,19)$. The findings of our work reflect the same outcome, as the disto-angular position of the tooth was found in $50 \%$ of the patients involved in our study. Class B or C was detected in 6 patients, with no preoperative $\mathrm{X}$-ray available in the remaining two patients.

An additional factor increasing the risk of fracture is a history of soft tissue inflammation around the tooth crown, such as pericoronitis $(10,14)$. In our study, a total of 4 patients $(50 \%)$ reported a history of chronic pericoronitis associated with the extracted tooth.

According to some professional authorities, the risk of any complications resulting from tooth removal is higher if the extraction is performed by personnel with less than three years of experience in the field (26-28). However, this topic remains controversial as other authors reported on it with different conclusions $(10,21)$.

A total of 7 patients underwent surgical reposition followed by stable osteosynthesis with plates and screws under general anesthesia. Only one patient was treated conservatively using intermaxillary fixation. Some authors report the conservative approach to be chosen more often. However, these works do not provide more detailed information about fractures $(6,11)$. In 7 cases of our study, the fractures were complicated with a severe displacement of bone fragments, and stable osteosynthesis with plates and screws was necessary.

The use of Winter's extraction elevator and similar instruments is also considered a significant risk factor for jaw fracture (14). The results of our study correspond with these findings as Winter's extraction elevator was used in 6 of 8 patients. Thus, we consider it relevant to comment on this outcome in detail.

The extraction elevator is a paired tool used mainly to extract tooth roots from their beds. We distinguish several types of these instruments, and the most commonly used are called Winter's (Figure 7) and Barry's (Figure 8) elevators. Although they are useful for root extraction, their use for other purposes, including the extraction of lower third molars, is controversial. In principle, elevators are levers and these simple tools amplify an input force to provide a greater output force. Since the resulting moment of force acting on both arms of the lever is given by the magnitude of the force multiplied by the length of the arm, it is thus inversely proportional to the length of the arms (29). In Winter's extraction elevator, the handle and the working end are arms of the lever. As the average length of the handle is $90 \mathrm{~mm}$ and the average length of the working end is $8-9 \mathrm{~mm}$, the force applied at the working side is approximately 10 times higher. As evidenced by examples from clinical practice and also by a number of studies published on this topic, the mechanically weakened area of the mandible angle may not always withstand the action of such a force $(30,31)$. Mandible fracture risk factors include age over 37 years, the presence of bone pathological lesions, tooth impaction, and the high ratio of tooth height in relation to the remaining bone height (9). If this ratio is greater than $50 \%$, and if the roots of the tooth overlap or are close to the mandibular canal, it is necessary to consider whether tooth removal is necessary. If so, extra care must be taken during the extraction as the jaw fracture risk is impending $(12,32)$. Such a risk is imminent if elevators are used for tooth extraction in older patients where ankylosis is more frequent (33). If nerve damage or an increased risk of lower jaw fracture due to tooth position is anticipated, coronectomy is also a possible option. This procedure is recommended in patients older than 25 years but is contraindicated in cases of the horizontal position of the lower third molar or if the molar is closely related to a tumor or a cyst $(34,35)$

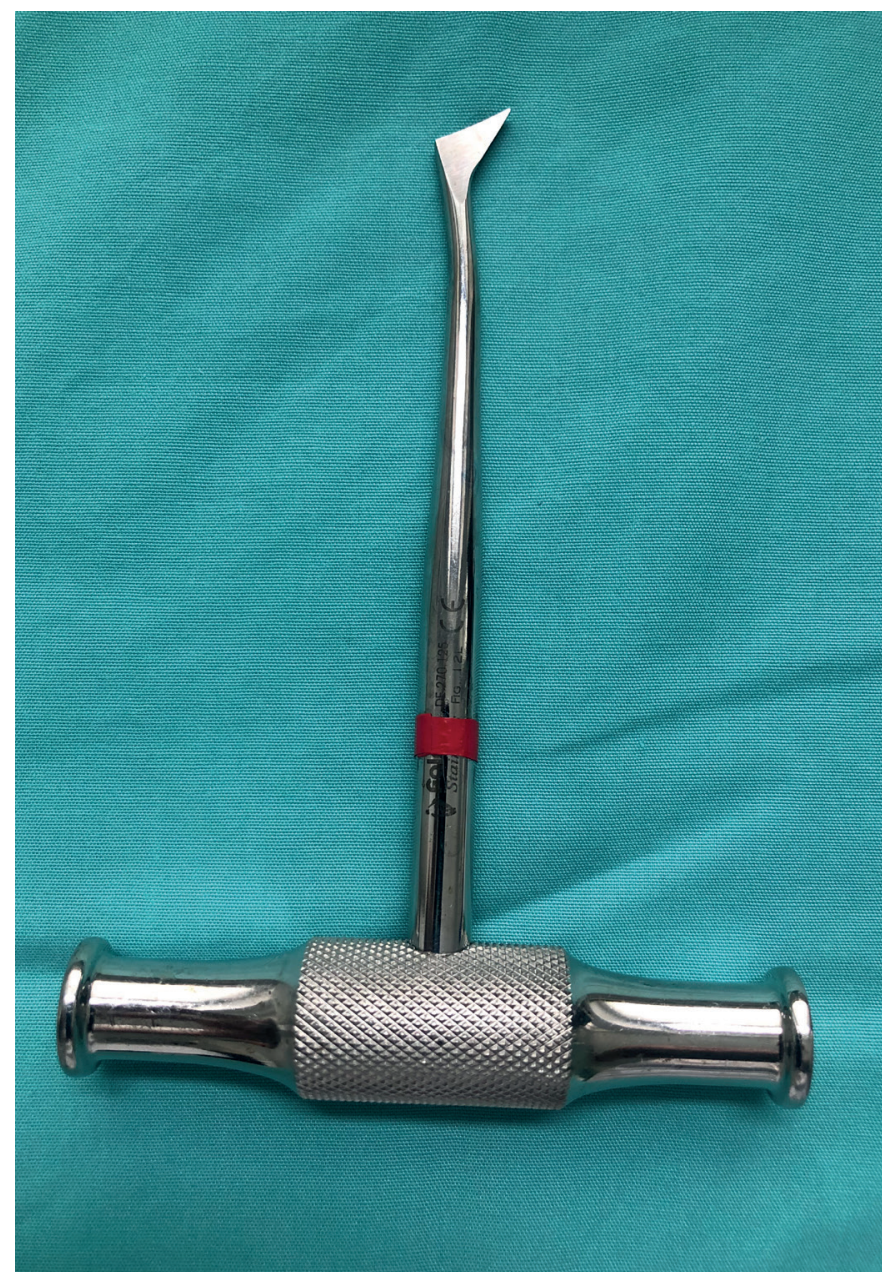

Fig. 7 Winter's elevator. 


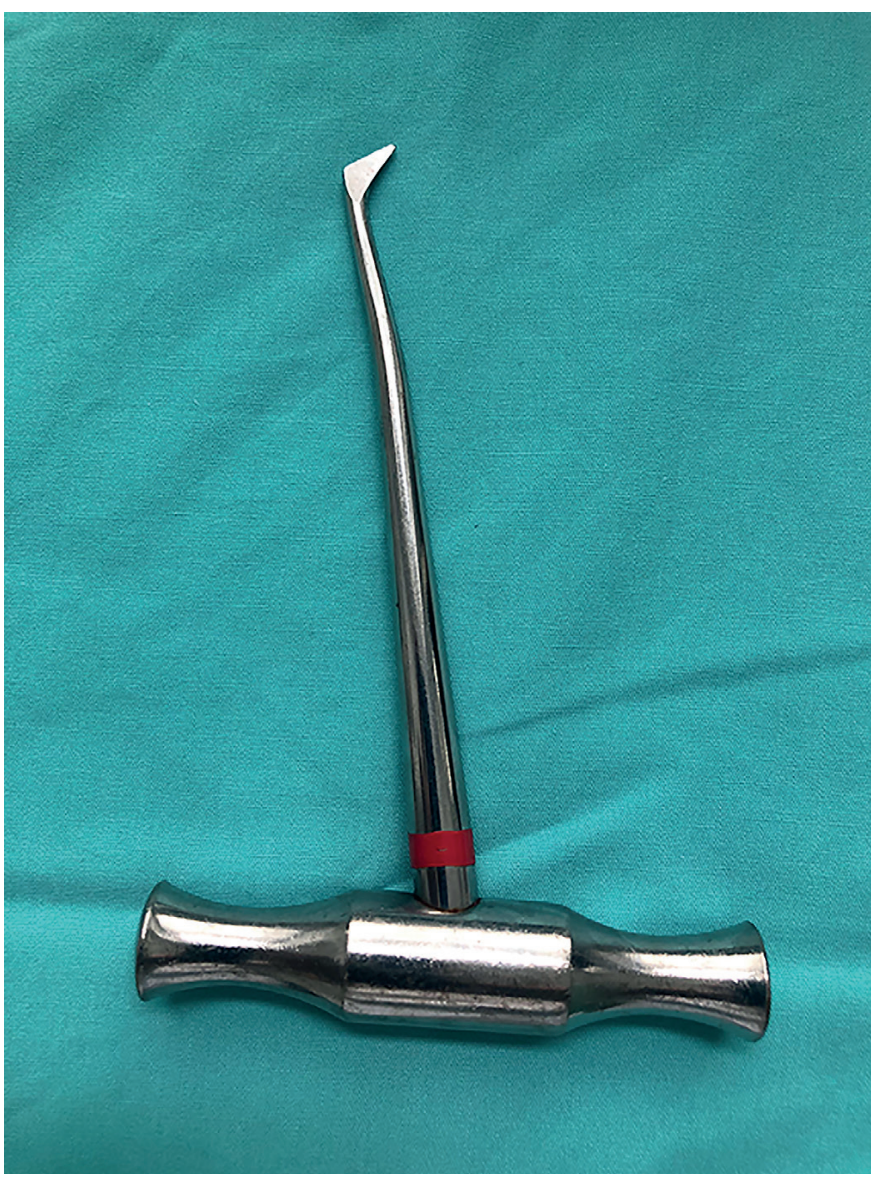

Fig. 8 Barry's elevator.

\section{CONCLUSION}

Before the extraction of any lower molar, and especially before the extraction of a lower third molar, the surgeon must always take into account any and all factors that may increase the risk of a mandibular fracture. It is necessary to have a preoperative X-ray, preferably an orthopantomogram. In some cases, e.g., intimate proximity of the tooth roots to the mandibular canal or unclear anatomy of the roots, cone-beam computed tomography (CBCT) targeting the mandibular angle region and the lower third molar position is recommended. Such an examination provides a $3 \mathrm{D}$ reconstruction of the roots and adjacent tissues arrangement. To prevent further complications, any excessive bone loss during the extraction should be avoided. It is advisable to remove the tooth in pieces to avoid any excessive bone drilling and especially preserve the area of linea obliqua externa.

Special care should be taken when using dental elevators. These tools allow the surgeon to exert a great force, which, if used improperly, can lead to jaw fracture. This was demonstrated even in our study as 6 of 8 (75\%) iatrogenic mandible fractures resulted from the use of Winter's elevator during the tooth removal. Thus, the exerted force shall be always applied very carefully after all risk factors have been considered.

Prior to the extraction, all patients should be made aware of the eventual risks, including the mandible fracture. A soft diet should be recommended for at least 3-4 weeks to every patient who underwent a complicated extraction.

The extraction of lower permanent molars, especially lower third molars, is considered to be a very difficult and risky procedure within dentoalveolar surgery. Taking this into consideration, if all recommendations and guidelines are followed in the preoperative examination and operative procedure, the risk of an iatrogenic fracture of the lower jaw remains very low.

\section{FUNDING}

The study was financially supported by the Charles University's program PROGRES Q29.

\section{REFERENCES}

1. Chiapasco M, De Cicco L, Marrone G. Side effects and complications associated with third molar surgery. Oral Surg Oral Med Oral Pathol 1993; 76: 412-20.

2. Osborn TP, Frederickson G, Jr., Small IA, et al. A prospective study of complications related to mandibular third molar surgery. J Oral Maxillofac Surg 1985; 43: 767-9.

3. Benediktsdottir IS, Hintze H, Petersen JK, et al. Accuracy of digital and film panoramic radiographs for assessment of position and morphology of mandibular third molars and prevalence of dental anomalies and pathologies. Dentomaxillofac Radiol 2003; 32: 109-15.

4. Pell GJ, Gregory GT. Report on a ten-year study of a tooth division technique for the removal of impacted teeth. Am J Orthod Dentofacial Orthop 1942; 28: B660-B666.

5. Winter GB. Principles of exodontia as applied to the impacted mandibular third molar: a complete treatise on the operative technic with clinical diagnoses and radiographic interpretations, St. Louis, Mo.: American Medical Book Company, 1926.

6. Joshi A, Goel M, Thorat A. Identifying the risk factors causing iatrogenic mandibular fractures associated with exodontia: a systemic meta-analysis of 200 cases from 1953 to 2015. Oral Maxillofac Surg 2016; 20: 391-6.

7. Alling CC, 3rd, Catone GA. Management of impacted teeth. J Oral Maxillofac Surg 1993; 51: 3-6.

8. Nyul L. Kieferfrakturen bei zahnextrationen. Zahnarztl Welt 1959; 60: $1-5$.

9. Libersa P, Roze D, Cachart T, et al. Immediate and late mandibular fractures after third molar removal. J Oral Maxillofac Surg 2002; 60: 163-5; discussion 165-6.

10. Perry PA, Goldberg MH. Late mandibular fracture after third molar surgery: a survey of Connecticut oral and maxillofacial surgeons. J Oral Maxillofac Surg 2000; 58: 858-61.

11. Ethunandan M, Shanahan D, Patel M. Iatrogenic mandibular fractures following removal of impacted third molars: an analysis of 130 cases. Br Dent J 2012; 212: 179-84.

12. Iizuka T, Tanner S, Berthold H. Mandibular fractures following third molar extraction. A retrospective clinical and radiological study. Int J Oral Maxillofac Surg 1997; 26: 338-43.

13. Krimmel M, Reinert S. Mandibular fracture after third molar removal. J Oral Maxillofac Surg 2000; 58: 1110-2.

14. Grau-Manclús V, Gargallo-Albiol J, Almendros-Marqués N, et al. Mandibular fractures related to the surgical extraction of impacted lower third molars: a report of 11 cases. J Oral Maxillofac Surg 2011; 69: 1286-90.

15. Kao YH, Huang IY, Chen CM, et al. Late mandibular fracture after lower third molar extraction in a patient with Stafne bone cavity: a case report. J Oral Maxillofac Surg 2010; 68: 1698-700.

16. Lyons CJ, Bruce RA, Frederickson GC, et al. Age of patients and morbidity associated with mandibular third molar surgery. J Am Dent Assoc 1980; 101: 240-5.

17. Wagner KW, Otten JE, Schoen R, et al. Pathological mandibular fractures following third molar removal. Int J Oral Maxillofac Surg 2005; 34: 722-6.

18. Pippi R, Solidani M, Broglia S, et al. Prevention of mandibular fractures caused by difficult surgical extractions: report of a borderline case. J Oral Maxillofac Surg 2010; 68: 1162-5. 
19. Cutilli T, Bourelaki T, Scarsella S, et al. Pathological (late) fractures of the mandibular angle after lower third molar removal: a case series. J Med Case Rep 2013; 7: 121.

20. Raymond M, Pontier D, Dufour A-B, et al. Frequency-dependent maintenance of left handedness in humans. Proc Royal Soc B 1996; 263: 1627-33.

21. Bodner L, Brennan PA, McLeod NM. Characteristics of iatrogenic mandibular fractures associated with tooth removal: review and analysis of 189 cases. Br J Oral Maxillofac Surg 2011; 49: 567-72.

22. Antic S, Milicic B, Jelovac DB, et al. Impact of the lower third molar and injury mechanism on the risk of mandibular angle and condylar fractures. Dent Traumatol 2016; 32: 286-95.

23. Reitzik M, Lownie JF, Cleaton-jones P, et al. Experimental fractures of monkey mandibles. Int J Oral Surg 1978; 7: 100-3.

24. Fuster Torres M, Gargallo Albiol J, Berini Aytés L, et al. Evaluation of the indication for surgical extraction of third molars according to the oral surgeon and the primary care dentist. Experience in the Master of Oral Surgery and Implantology at Barcelona University Dental School. J Medicina Oral, Patología Oral y Cirugia Bucal 2008; 13: 499-504.

25. Chrcanovic BR, Custodio AL. Considerations of mandibular angle fractures during and after surgery for removal of third molars: a review of the literature. Oral Maxillofac Surg 2010; 14: 71-80.

26. Sisk AL, Hammer WB, Shelton DW, et al. Complications following removal of impacted third molars: the role of the experience of the surgeon. J Oral Maxillofac Surg 1986; 44: 855-9.
27. Niedzielska I, Kowol I. Iatrogenic injury during extraction of lower molar teeth. Dent Med Probl 2009; 46: 501-5.

28. Woldenberg Y, Gatot I, Bodner L. Iatrogenic mandibular fracture associated with third molar removal: Can it be prevented? J Medicina Oral, Patología Oral y Cirugía Bucal 2007; 12: 70-2.

29. Kandler H. The design and construction of dental elevators. J Dent 1982; 10: 317-22.

30. Bonardi JP, Momesso GAC, Lima VNd, et al. Etiological factors for mandibular fractures in transoperative period of tooth extraction: systematic review. Research, Society and Development 2020; 9: e721997856.

31. Hiregoudar JS. Iatrogenic fracture of mandible, due to Improper Elevator Technique. Indian J Dent Adv 2012; 4: 995-7.

32. Meechan JG. The effect of mandibular third molar presence and position on the risk of an angle fracture. J Oral Maxillofac Surg 2000; 58: 399 .

33. Mamoun J. Use of elevator instruments when luxating and extracting teeth in dentistry: clinical techniques. J Korean Assoc Oral Maxillofac Surg 2017; 43: 204-11.

34. Gady J, Fletcher MC. Coronectomy: indications, outcomes, and description of technique. Atlas Oral Maxillofac Surg Clin North Am 2013; 21: 221-6.

35. Long H, Zhou Y, Liao L, et al. Coronectomy vs. total removal for third molar extraction: a systematic review. J Dent Res 2012; 91: 659-65. 